



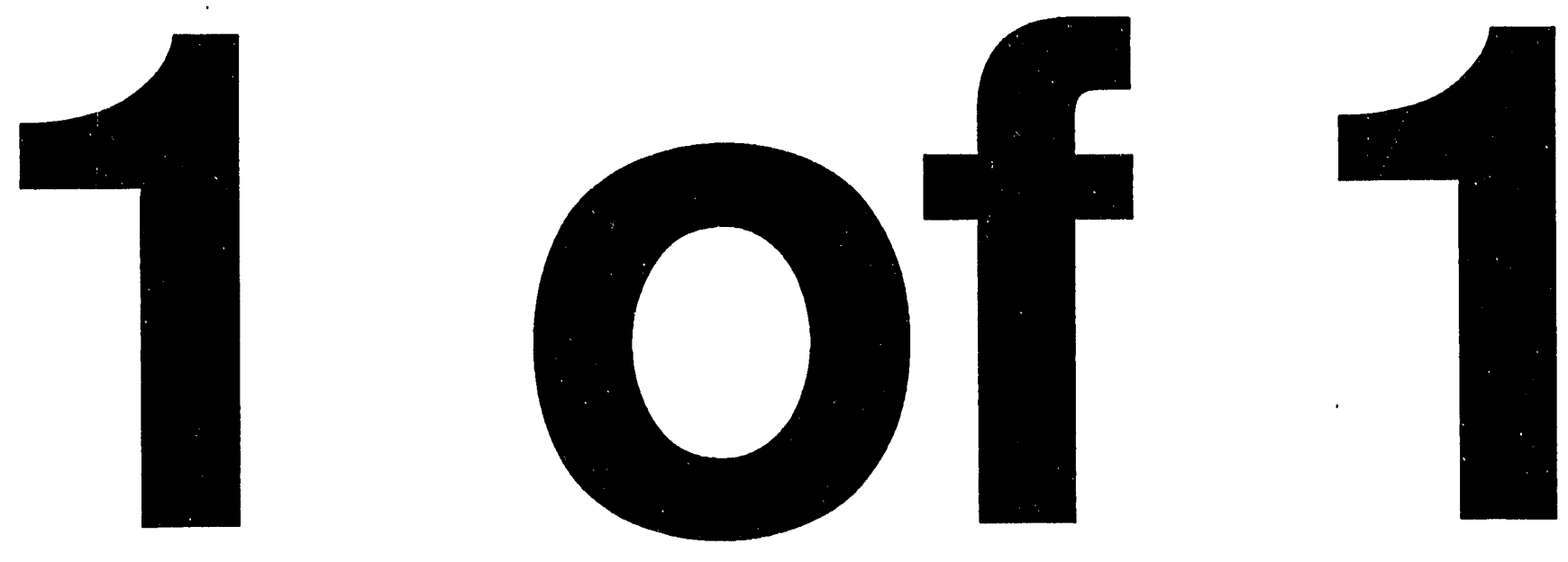
SAND94-8201

Unlimited Release

Printed October 1993

\title{
SALT DEPOSITION STUDIES IN A SUPERCRITICAL WATER OXIDATION REACTOR (INTERIM REPORT)
}

\author{
C. A. LaJeunesse \\ S. F. Rice \\ R. G. Hanush \\ J. D. Aiken \\ Engineering and Combustion Technology Departments \\ Sandia National Laboratories
}

\begin{abstract}
Supercritical water oxidation ( $\mathrm{SCV}, \mathrm{O})$, a method for destroying aqueous organic waste, is a relatively new technology discovered about fifteen years ago. SCWO occurs at moderate temperatures and pressures where the ability of water to dissolve hydrocarbons and other organic chemicals is greatly enhanced. Depending on the feed stream and residence time, the dissolved organic waste reacts with an oxidizer to produce innocuous combustion products.

However, oxidation of organic material containing heteroatoms, such as sulfur or phosphorous, forms sulfuric or phosphoric acid in the absence of metal ions. In situ neutralization with sodium hydroxide then forms salts that are insoluble at supercritical conditions. These salts deposit in the reactor affecting the processing of the organic material.

To design a system that can accommodate the formation of these salts, it is important to understand the deposition process quantitatively. This paper is an interim report on an experimental program designed to understand the salt deposition phenomena.
\end{abstract}




\section{Contents}

Introduction $\quad 4$

$\begin{array}{ll}\text { Experimental } & 4\end{array}$

Results and Discussion $\quad 6$

Scale-up Estimates $\quad 8$ 


\section{Illustrations}

No.

1. Temperature profile for all seven tests.

2. Test \#1 pressure traces $\left(0.5 \mathrm{wt} \% \mathrm{Na}_{2} \mathrm{SO}_{4}, \dot{\mathrm{m}}=0.6 \mathrm{~g} / \mathrm{s}\right)$.

3. Test \#2 pressure traces $\left(0.5 \mathrm{wt} \% \mathrm{Na}_{2} \mathrm{SO}_{4}, \dot{\mathrm{m}}=1.2 \mathrm{~g} / \mathrm{s}\right)$.

4. Test \#3 pressure traces $\left(0.5 \mathrm{wt} \% \mathrm{Na}_{2} \mathrm{SO}_{4}, \dot{\mathrm{m}}=1.5 \mathrm{~g} / \mathrm{s}\right)$.

5. Test \#4 pressure traces $\left(0.5 \mathrm{wt} \% \mathrm{Na}_{2} \mathrm{SO}_{4}, \mathrm{~m}=0.6 \mathrm{~g} / \mathrm{s}\right)$.

6. Test \#5 pressure traces $\left(0.5 \mathrm{wt} \% \mathrm{Na}_{2} \mathrm{SO}_{4}, \mathrm{~m}=1.2 \mathrm{~g} / \mathrm{s}\right)$.

7. Test \#6 pressure traces $\left(0.5 \mathrm{wt} \% \mathrm{Na}_{2} \mathrm{SO}_{4}, \mathrm{~m}=0.6 \mathrm{~g} / \mathrm{s}\right)$.

8. Test \#7 pressure traces $\left(0.5 \mathrm{wt} \% \mathrm{Na}_{2} \mathrm{SO}_{4}, \dot{\mathrm{m}}=0.6 \mathrm{~g} / \mathrm{s}\right)$.

9. Plot of the four thermocouples covering the last $350 \mathrm{~cm}$ of 16 the reactor.

\section{Tables}

No.

1. Test conditions for $\mathrm{Na}_{2} \mathrm{SO}_{4}$ experiment.

2. Time that the $\mathrm{Na}_{2} \mathrm{SO}_{4}$ is discontinued. 


\section{Introduction}

Salt deposition and subsequent flow system fouling is generally recognized as an important technical issue surrounding the practical applicability of supercritical water oxidation (SCWO) to the destruction of toxic chemicals and other hazardous materials. This interim report is intended to describe preliminary results of experiments in a tubular SCWO flow system examining the deposition of sodium sulfate. The interpretation of these experiments allows us to suggest a view of the overall deposition process and to present a method to translate these test reactor results to a parameterized predictive model for system scale-up.

Salts found in the flow system of a supercritical water reactor originate from several sources. Of particular importance are salts formed from the oxidation of organic material containing heteroatoms such as sulfur or phosphorous. In the absence of metal ions, this kind of process will form sulfuric or phosphoric acid. Because of corrosivity.concerns associated with acidic flows, many operational schemes involve neutralizing these acids with a base such as sodium hydroxide. The overall process of oxidation and in situ neutralization will produce sodium sulfate and sodium phosphate; salts that are essentially insoluble at typical SCWO reactor conditions. To design a system that can accommodate the formation of these salts, it will be important to understand the deposition and clogging process quantitatively.

We emphasize that these results are preliminary and that additional test runs are scheduled to examine the salt deposition process with other salts. Chemical analysis of samples taken of the reactor effluent during the plugging process is ongoing and will contribute to a more complete understanding of deposition and plugging processes.

\section{Experimental}

\section{Reactor configuration}

All tests were performed in Sandia's SCW flow reactor. The reactor is approximately $750 \mathrm{~cm}$ long, with two $90^{\circ}$ turns at 260 and $300 \mathrm{~cm}$. Thermocouples are located in the flow approximately every $60 \mathrm{~cm}$ at T-unions joining individual sections of 9/16 in. O.D. - 3/16 in. I.D. Inconel 625 tubing.

The first $260 \mathrm{~cm}$ of the reactor is equipped with heaters capable of adding power at a rate of 17 watts $/ \mathrm{cm}$, the second section is powered at a rate of 5.4 watts $/ \mathrm{cm}$. Pressure transducers are placed at three locations. PT1 is at the inlet to the reactor before any heaters. PT2 is located $140 \mathrm{~cm}$ into the reactor in the initial heat-up section. PT3 is located at the end of the system just before the pressure letdown regulator. The readings of these transducers are recorded continuously throughout a test such that the development of a plug or 
constriction can be detected as a pressure differential from one transducer to the next. With PT2 located in the reactor itself, some spatial resolution on the location of the plug can be gained. The focus of this report is the interpretation of seven tests and their associated pressure transducer traces.

\section{Operational methods}

$\mathrm{Na}_{2} \mathrm{SO}_{4}$ at $0.5 \mathrm{wt} \%$ in distilled water was heated to approximately $400^{\circ} \mathrm{C}$ to quantify the deposition rate of $\mathrm{Na}_{2} \mathrm{SO}_{4}$ over a range of several pressures, flow rates, and heating rates. Tests $1,3,4,5$, and 6 used the basic procedure outlined below. Tests 2 and 7 were similar to the other five, but instead of simply discontinuing the experiment upon formation of a plug, an attempt was made to clear out the plug while the reactor was still operating. Temperature profiles along the reactor are steep for Test 1 and Test 4, and more gradual for Tests 2, 3, 5,6 , and 7 . Table 1 shows the conditions used for these different tests.

\section{Procedure:}

1) Distilled water was used during initial heat-up while a stable temperature profile was established along the reactor. These profiles are shown in Figure 1.

2) After steady state was reached, the water was discontinued and distilled water with $0.5 \mathrm{wt} \% \mathrm{Na}_{2} \mathrm{SO}_{4}$ was substituted for pure water.

3) Samples of the liquid effluent were collected during the experiment every 5 to 10 minutes.

4) As a plug formed, a pressure differential greater than approximately $1000 \mathrm{psi}$ eventually occurred. The test was terminated by shutting off power to the heaters, releasing pressure at the letdown regulator, and turning off the flow of $\mathrm{Na}_{2} \mathrm{SO}_{4}$ solution.

5) After the reactor had cooled, the plug was redissolved by flowing pure water at 2000 psi and collecting all effluent to provide a global salt balance. Evaluation of the effluent by ion specific electrode and spectrophotometric techniques yields a deposition rate for sodium sulfate under the above conditions. This analysis is still underway, but preliminary results indicate that at least $95 \%$ of the input salt does not emerge and therefore must be deposited in the reactor during a test.

Modified procedure for Tests $2 \&$ 7: As plugging occurred during Tests 2 and 7 , heating and $\mathrm{Na}_{2} \mathrm{SO}_{4}$ were discontinued. Water was then reintroduced into the reactor to redissolve the salt plug as the temperature fell. 


\section{Results and Discussion}

Pressure data is shown in Figures 2 through 8 . Plugging times ranged from 18 to 48 minutes and are summarized in Table 2 . Three operational parameters were varied over these seven tests. These were flow rate, temperature profile, and pressure. The operating conditions for the different tests are listed in Table 1.

Tests 6,2 and 3 varied flow rate over the available range of the equipment at approximately $3700-4000$ psi. Test 1 is similar to Test 6 , but the temperature profile had a much more rapid heat up stage. Test 4 had the same procedure and thermal profile as Test 1 with the pressure elevated to 5150 psi. Test 5 compares with Test 2 with similar flow rates, thermal profiles, but again the pressure was increased to $5150 \mathrm{psi}$. Test 7 is the same as Test 6 with an attempt to clear the plug. Test 2 also included an attempt to clear the plug while still operating.

Figure 2, representing Test 1, displays typical pressure traces. About 18 minutes after the salt is introduced to the flow, pressure at PT1 begins to increase while PT2 and PT3 remain at the regulator pressure. This indicates that a plug is building up at a point in the first $140 \mathrm{~cm}$ of the reactor before the PT2 pressure transducer. Note that the temperature curve in Figure 1 for Test 1 has a very rapid rise in temperature. The temperature that the fluid transitions from liquidlike to gaslike densities, which is approximately the critical temperature $\left(374^{\circ} \mathrm{C}\right)$, is located in this region. The simplest conclusion based on the trace is that the salt is precipitating out of solution over a fairly short length of the tube. It may be possible for this plug to break away and move downstream as appears to occur at 22.5 minutes. However, eventually a major plug forms and the reactor must be shut down. Because the reactor is vented at the pressure regulator, the PTI trace lags a few minutes behind the others as the fluid behind the plug slowly leaks through.

\section{Flow rate}

The simplest way to compare the effect of flow rate is to examine the time to formation of a plug on Tests 6,2 and 3. Comparing Test $6(0.6 \mathrm{~g} / \mathrm{s})$ and Test 2 $(1.2 \mathrm{~g} / \mathrm{s})$ shows a plug forming more rapidly at the higher flow rate, going from approximately 48 minutes to 23 minutes. This is to be expected since the higher flow rate is accompanied with a higher rate of salt being injected into the system. Analysis of the effluent during these runs indicated that all of the sodium sulfate in the input stream is deposited in the reactor. These results suggest that at the lower flow rates, the rate that the plug forms is proportional to the rate that salt is injected into the reactor. Note that the plugging time on Test 2 is about half the time for Test 6.

Increasing the flow rate from $1.2 \mathrm{~g} / \mathrm{s}$ to $1.5 \mathrm{~g} / \mathrm{s}$ resulted in a plug forming in 38 minutes. This result seems to conflict with the results of Tests $6 \& 2$ with the higher flow rate of $1.5 \mathrm{~g} / \mathrm{s}$ resulting in a longer plug formation time than the 1.2 
$\mathrm{g} / \mathrm{s}$ of Test 2. Analysis of the effluent indicated that all of the salt was still being deposited within the reactor. The higher flow rate may be causing the salt to be spread out and adhere over a larger region in the reactor and consequently taking longer to finally close off the tube. Note that the rise in pressure from 4000 psi to 5000 psi also takes longer in Test 3.

\section{Pressure}

The effect of pressure can be evaluated by comparing Test 1 with Test $4(0.6$ $\mathrm{cc} / \mathrm{sec}$, steep thermal profile) and Test 2 with Test $5(1.2 \mathrm{cc} / \mathrm{sec}$, gradual thermal profile). In both cases, the higher pressure conditions produced a plugged reactor slightly faster than at lower pressure.

\section{Temperature profile}

We can compare Test 1 with Tests 6 and 7 to see the effect of changing the thermal profile of the reactor. A plug forms much faster in the more rapidly heated Test 1 ( 28 minutes) than in Test 6 (48 minutes) or Test 7 (41 minutes). This is probably the result of having a longer stretch of tubing for the salt to precipitate over such that this plug does not completely close off the tube until a more elongated plug is formed. Note that on Test 1 that PT2 remains at low pressure as the plug forms, indicating that the plug forms before this transducer located $140 \mathrm{~cm}$ into the reactor. On Tests 6 and 7, PT2 follows PT1 showing the formation of the plug is farther downstream.

\section{Clearing Plugs}

After plugging occurred during Test 2 (the first peak in Figure 3 at 23 minutes), the $\mathrm{Na}_{2} \mathrm{SO}_{4}$ and heat were turned off and an attempt was made to clear the plug by flowing pure water through the reactor. The spikes that follow are due to the operator turning the input on and off to prevent a rupture disk from bursting and are not due to a plug clearing and then building up again. Eventually the plug was cleared at about 45 minutes and the $\mathrm{Na}_{2} \mathrm{SO}_{4}$ was reestablished.

A second attempt at actively clearing a plug was made in Test 7 (see Figure 8). This time the plug was cleared more systematically such that operator induced pressure fluctuations were avoided. All furnaces were turned off when the pressure on the upstream side of the plug had reached 5000 psi (about 42 minutes). The flow of $\mathrm{Na}_{2} \mathrm{SO}_{4}$ solution was then switched to pure water. The heat was turned off at 42 minutes and the temperatures rapidly dropped to below $380^{\circ} \mathrm{C}$ at 48 minutes. Upstream pressure began to decrease at 48 minutes after all thermocouples had fallen below $380^{\circ} \mathrm{C}$. The temperature at the thermocouples in the last $350 \mathrm{~cm}$ in the reactor are shown as a function of time in Figure 9. When the pressure drop had decayed to zero, the furnaces were turned on. At 52 minutes, the $\mathrm{Na}_{2} \mathrm{SO}_{4}$ flow was reestablished. At 95 minutes, upstream pressure again began to rise. This time $\mathrm{Na}_{2} \mathrm{SO}_{4}$ solution was changed to pure water and the furnaces were left on, but the pressure differential continued to 
grow and eventually shutdown was initiated. Apparently, the plug could not be cleared without reducing temperature.

Test 7 is consistent with work by Armellini and Tester (J. Supercrit. Fluids, $1991,4,254)$ on the phase diagram of $\mathrm{Na}_{2} \mathrm{SO}_{4}$ in water at supercritical pressure and temperatures. At $380^{\circ} \mathrm{C}, 0.55 \mathrm{wt} \%$ of salt can coexist in a single phase; any excess must precipitate out as a solid. As temperature increases, the solubility rapidly approaches zero.

\section{Scale-up Estimates}

The results reported above are useful for scaling-up from the bench scale to a pilot scale size with $2.5 \mathrm{wt} \%$ salt loading. As a rough estimate, we propose that the time to plugging is proportional to the time it takes to fill a "precipitation volume" with salt. This volume is determined by the crossectional area of the tube and the length of tubing over which material is deposited. The work of Armellini and Tester has shown that the solubility of $\mathrm{Na}_{2} \mathrm{SO}_{4}$ in SCW at 250 bar drops from $0.55 \mathrm{wt} \%$ at $380^{\circ} \mathrm{C}$ to less than $0.1 \mathrm{wt} \%$ at $400{ }^{\circ} \mathrm{C}$. The length of tube over which this temperature rise occurs will determine the volume that greater than $80 \%$ of the salt will fill. This produces the simple re'ationship,

$$
t_{\text {plug }}=\rho A L / c \dot{m},
$$

where $t_{\text {plug }}$ is the time to plug formation, $\rho$ is the specific gravity of sodium sulfate, $\mathrm{A}$ is the tubing crossectional area, $\mathrm{L}$ is the length of tubing over which the temperature changes from $380^{\circ} \mathrm{C}$ to $400^{\circ} \mathrm{C}, \mathrm{c}$ is the concentration of the salt by weight fraction, and $m$ is the total input flow rate by weight. Using Test 1 as an example, $c=0.005, \rho=2.68 \mathrm{~g} / \mathrm{cm}^{3}, \dot{\mathrm{m}}=0.6 \mathrm{~g} / \mathrm{sec}, \mathrm{A}=0.179 \mathrm{~cm}^{2}$, and $\mathrm{L}=20 \mathrm{~cm}$ (roughly estimated from Figure 1). These values yield a tplug of 53 minutes for Test 1 as compared with 28 minutes observed.

This calculation assumes that the salt comes out of solution instantaneously and uniformly. This estimate can be improved by recognizing that the solubility curve shows an exponential dependence on temperature such that nearly as much of the material will precipitate between $380^{\circ} \mathrm{C}$ and $385^{\circ} \mathrm{C}$ as will between $385^{\circ} \mathrm{C}$ and $400{ }^{\circ} \mathrm{C}$. If the simple relationship in Eq. 1 was corrected to include this non-linearity, the predicted time to plugging would be reduced.

To scale-up, thermal and kinematic similitude are maintained. For thermal similitude, the flow must be heated from 380 to $400{ }^{\circ} \mathrm{C}$ over the same length as in the bench test. For kinematic similitude, the velocities of the fluid particles in the scaled-up version, $\mathrm{V}_{\mathrm{s}}$, must equal the velocities in the tests above, $\mathrm{V}_{\mathrm{t}}$ :

$$
\mathrm{V}_{\mathrm{s}}=\mathrm{V}_{\mathrm{t}}
$$


If a $50 \mathrm{gal} / \mathrm{hr}$ reactor is desired, the scaled flowrate, $\mathrm{m}_{\mathrm{S}}$, is on the order of 50 times the test flowrates, $\mathrm{m}_{\mathrm{t}}$ :

$$
\begin{aligned}
& \dot{\mathrm{m}}_{\mathrm{s}}=50 \dot{\mathrm{m}}_{\mathrm{t}} \\
& \dot{\mathrm{m}}_{\mathrm{s}}=\rho_{\mathrm{s}} \mathrm{A}_{\mathrm{s}} \mathrm{V}_{\mathrm{s}}=50 \rho_{\mathrm{t}} \mathrm{A}_{\mathrm{t}} \mathrm{V}_{\mathrm{t}}
\end{aligned}
$$

where $\rho$ and $A$ are the water density and crossectional area of the tubes, respectively. Since $\rho_{s}=\rho_{t}$ and $V_{s}=V_{t}$,

$$
A_{s}=50 A_{t} .
$$

The inner diameter of the bench scale size reactor is 0.188 inch indicating that the pilot version should be 1.33 inch.

Plugging occurred on the order of 20 minutes or greater during the tests at $4000 \mathrm{psi}$ with salt loadings of $0.5 \mathrm{wt} \%$. Hence, plugging in the pilot reactor should occur in

$$
\begin{aligned}
& t_{\text {plug }}=20 \text { minutes } \times(0.5 w t \% / 2.5 w t \%) \\
& =4 \text { minutes. }
\end{aligned}
$$

The time to plugging in the tests, 20 minutes, is reduced in the case of the larger pilot system due to the increase in salt loading from $0.5 \mathrm{wt} \%$ to $2.5 \mathrm{wt} \%$. Although the tubing of the pilot version has an area 50 times that of the bench scale, it will still plug rapidly because the feed rate in a pilot version is also 50 times that of the bench scale.

The arguments above need to be supported by experimentation before final design. In addition, the above tests were conducted with hydrogen peroxide as the oxidizer. If air is the oxidizer, the additional experimentation should be done with air. However, if Eq. 1 is correct, the choice of oxidizer should not matter.

A final parameter to check to insure kinematic similitude is whether the flow regimes are similar for the pilot scale and bench scale. This is violated, somewhat, because the Reynolds number for the scaled version is several times the Reynolds number for the bench model. This means that the flow in the scaled-up version will transition quicker to turbulent flow. However, at $380^{\circ} \mathrm{C}$ and $1.2 \mathrm{~g} / \mathrm{s}$ flowrate, where the salt is precipitating out, the Reynolds number is approximately 5000 and is considered turbulent for heat transior purposes. Both the pilot and bench-scale sizes will have the same flow regimes at the temperature of interest.

Another salt that is of interest, $\mathrm{NaCl}$, will form from neutralization of chlorinated feed streams by $\mathrm{NaOH}$. Armellini and Tester have analyzed in detail the temperature-composition diagram for $\mathrm{NaCl}$ and water. The supercritical 
mixture will transition through a vapor-liquid region, and finally into a vaporsolid region where, we believe, it will plug the reactor at about $460^{\circ} \mathrm{C}$. We intend to begin exploring this soon.

In summary, the major technical problem to overcome to be able to use SCWO to destroy toxic wastes and other hazardous material is the formation of salts and their subsequent deposits following oxidation of the organic itself. This work provides an understanding of salt formation for review and provides a framework and focus for developing a tubular reactor. 
Table 1. Test conditions for $\mathrm{Na}_{2} \mathrm{SO}_{4}$ experiment

\begin{tabular}{|c|c|}
\hline Test No. & Pressure (psi) \\
\hline 1 & 3700 \\
\hline 2 & 3700 \\
\hline 3 & 3700 \\
\hline 4 & 5150 \\
\hline 5 & 5150 \\
\hline 6 & 3700 \\
\hline 7 & 3700 \\
\hline
\end{tabular}

Temperature Profile

(steep/gradual)

steep
gradual
gradual
steep
gradual
gradual
gradual

Flow rate $(\mathrm{g} / \mathrm{s})$

0.6

1.2

1.5

0.6

1.2

0.6

0.6

Table 2. Time that $\mathrm{Na}_{2} \mathrm{SO}_{4}$ is discontinued.

Test No.

1

2

3

4

5

6

7
Time (minutes)

28

23

37

26

18

48

41 


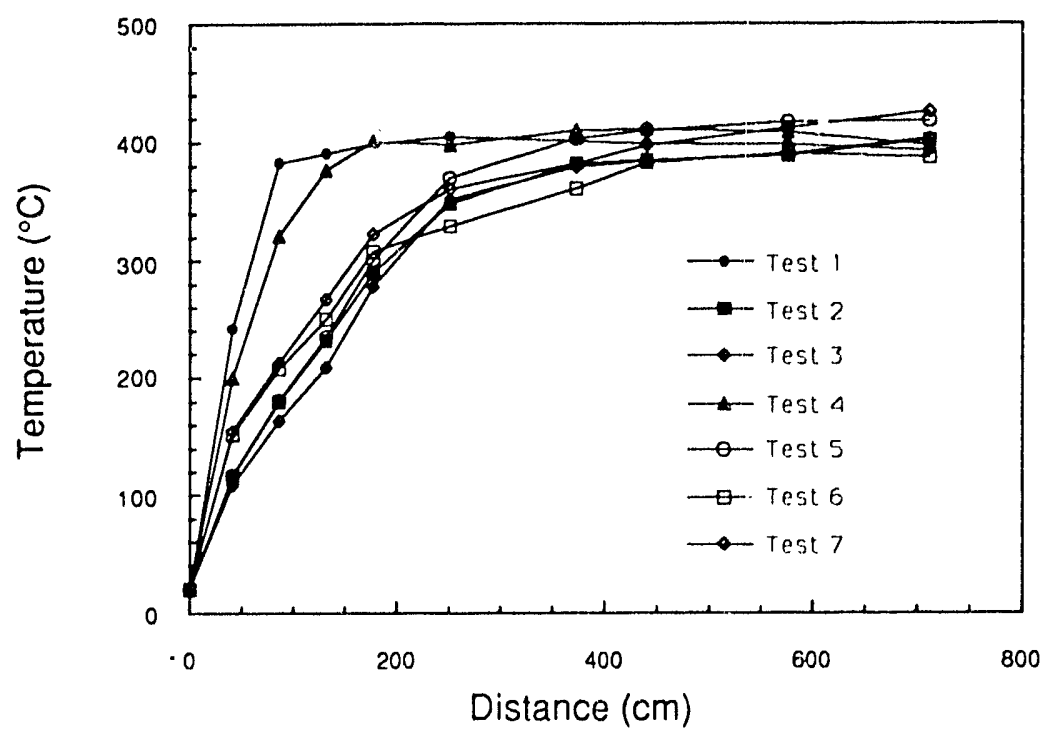

Figure 1: Temperature profile for all seven tests.

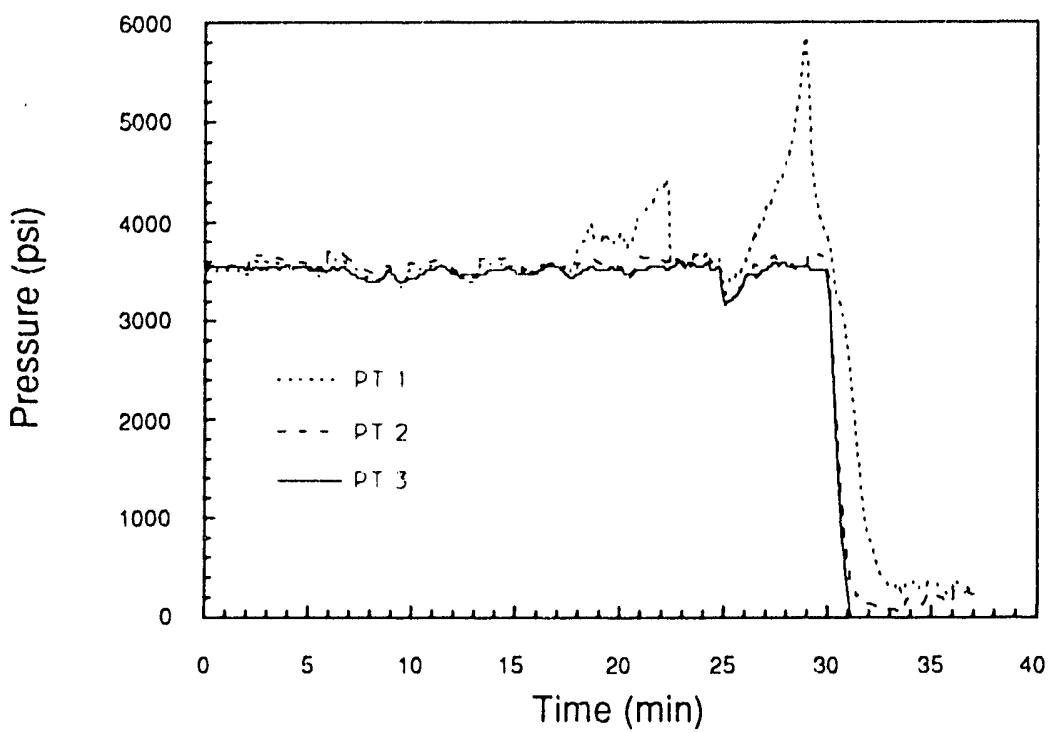

Figure 2: Test \#1 pressure traces $\left(0.5 \mathrm{wt} \% \mathrm{Na}_{2} \mathrm{SO}_{4}, \dot{\mathrm{m}}=0.6 \mathrm{~g} / \mathrm{s}\right)$. 


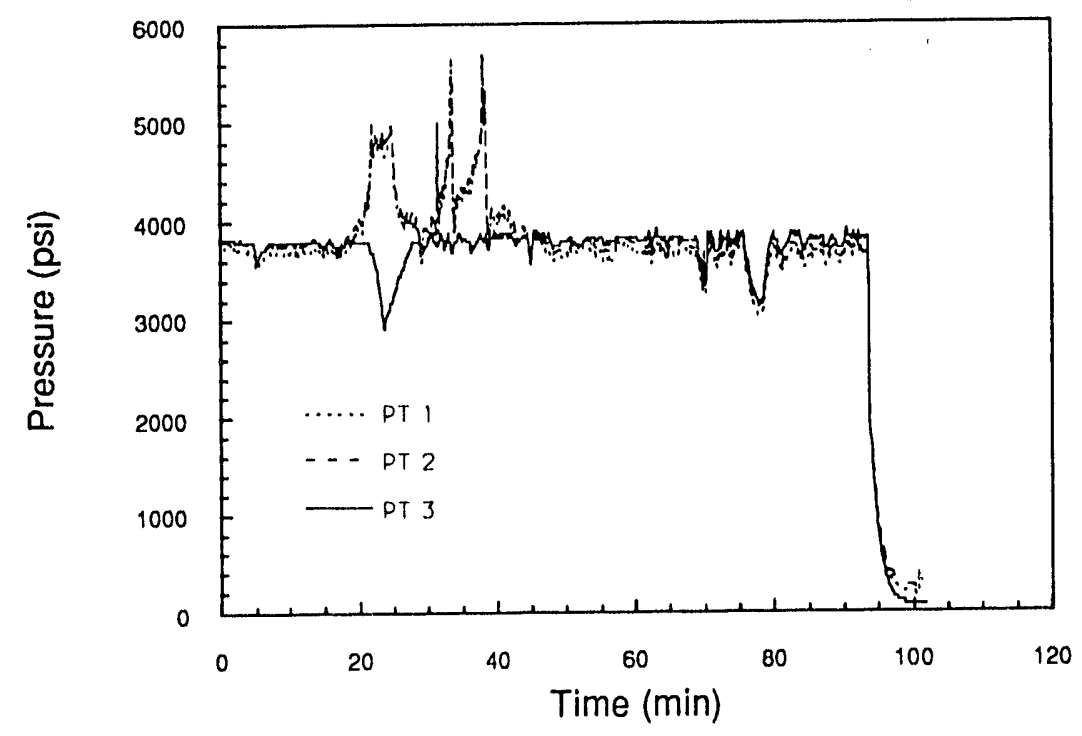

Figure 3: Test \#2 pressure traces $\left(0.5 \mathrm{wt} \% \mathrm{Na}_{2} \mathrm{SO}_{4}, \mathrm{~m}=1.2 \mathrm{~g} / \mathrm{s}\right)$.

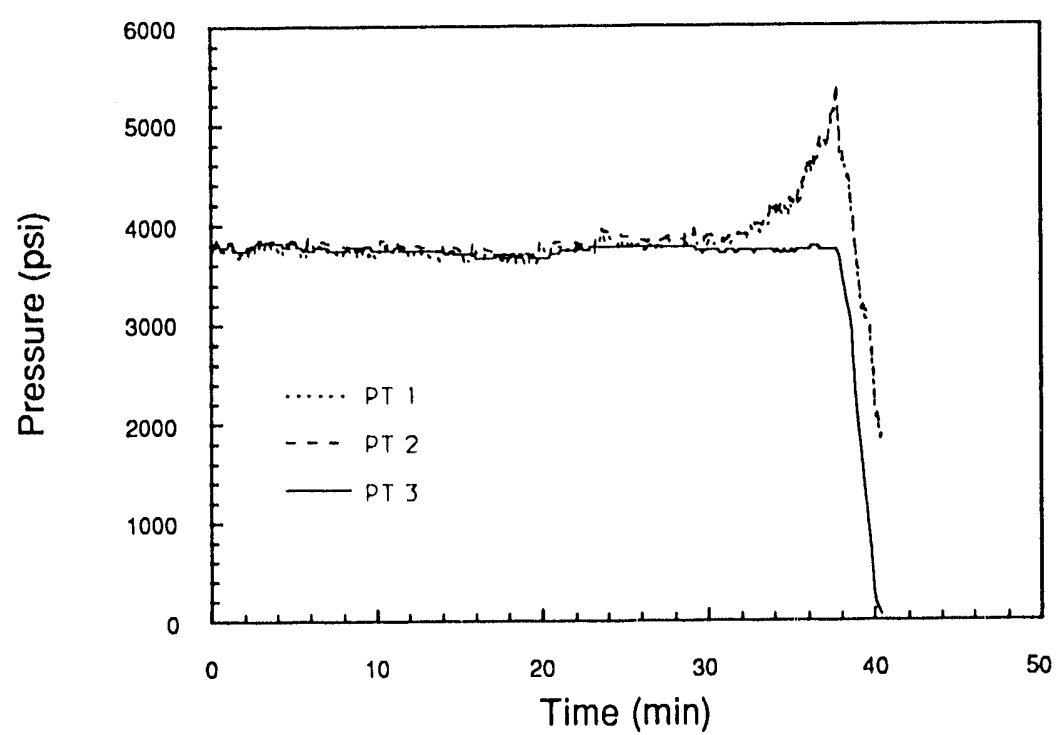

Figure 4: Test \#3 pressure traces $\left(0.5 \mathrm{wt} \% \mathrm{Na}_{2} \mathrm{SO}_{4}, \dot{\mathrm{m}}=1.5 \mathrm{~g} / \mathrm{s}\right)$. 


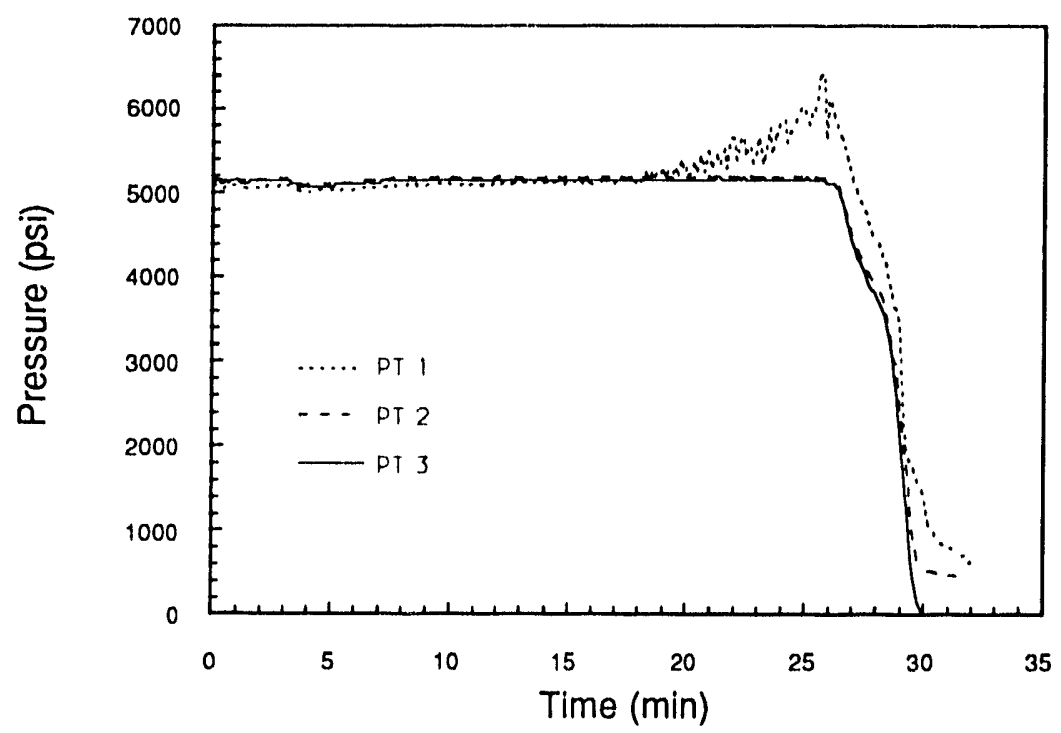

Figure 5: Test \#4 pressure traces $\left(0.5 \mathrm{wt} \% \mathrm{Na}_{2} \mathrm{SO}_{4}, \dot{\mathrm{m}}=0.6 \mathrm{~g} / \mathrm{s}\right)$.

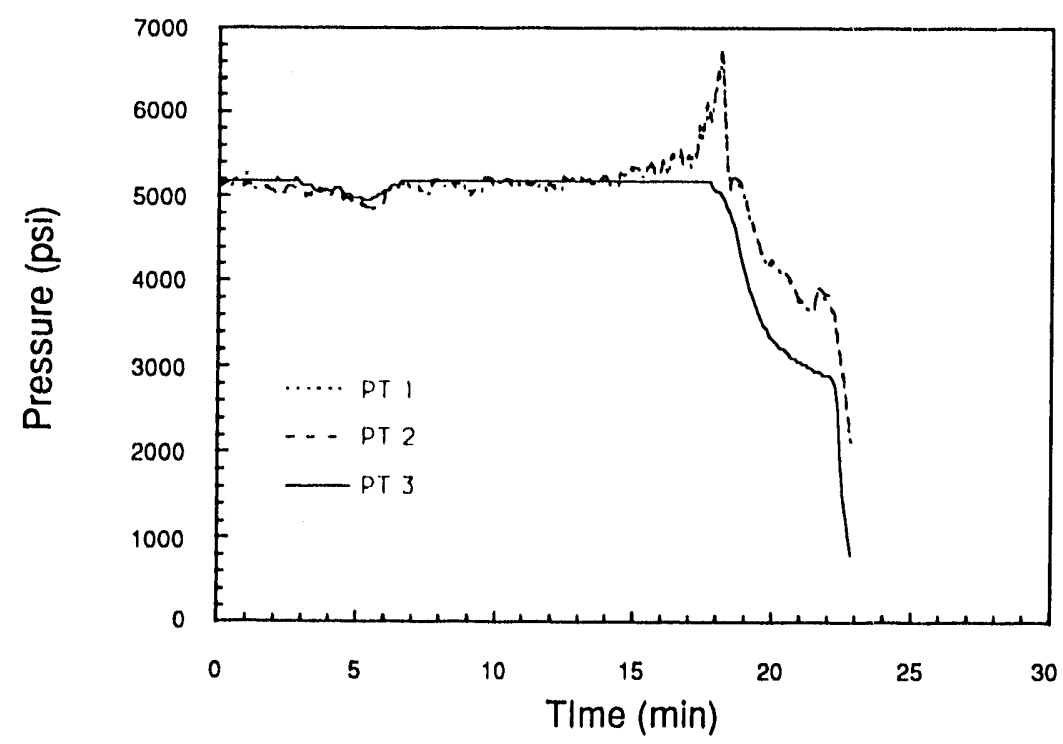

Figure 6: Test \#5 pressure traces $\left(0.5 \mathrm{wt} \% \mathrm{Na}_{2} \mathrm{SO}_{4}, \dot{\mathrm{m}}=1.2 \mathrm{~g} / \mathrm{s}\right)$. 


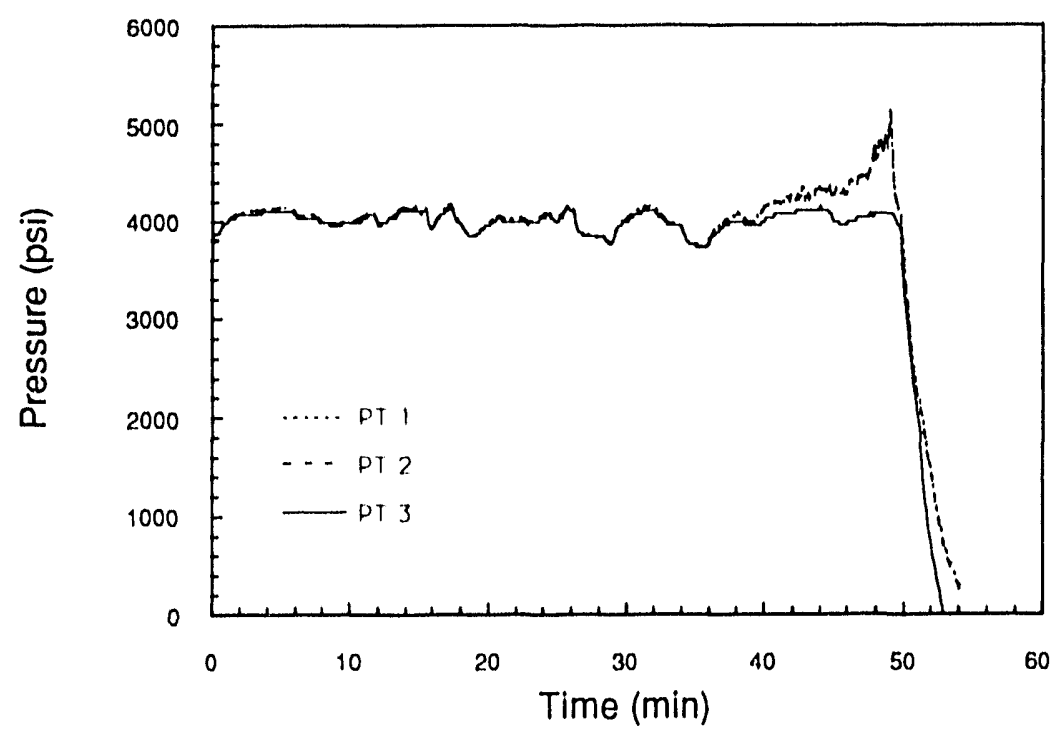

Figure 7: Test \#6 pressure traces $\left(0.5 \mathrm{wt} \% \mathrm{Na}_{2} \mathrm{SO}_{4}, \mathrm{~m}=0.6 \mathrm{~g} / \mathrm{s}\right)$.



Figure 8: Test \#7 pressure traces $\left(0.5 \mathrm{wt} \% \mathrm{Na}_{2} \mathrm{SO}_{4}, \dot{\mathrm{m}}=0.6 \mathrm{~g} / \mathrm{s}\right)$. 




Figure 9: Plot of the four thermocouples covering the last $350 \mathrm{~cm}$ of the reactor. Positions of thermocouples: $\mathrm{T} 1=370 \mathrm{~cm}, \mathrm{~T} 2=440 \mathrm{~cm}, \mathrm{~T} 3=570 \mathrm{~cm}$, $\mathrm{T} 4=710 \mathrm{~cm}$. 
UNLIMITED RELEASE

\section{INITIAL DISTRIBUTION}

D. C. Cossey

CEO

Innotek

1300 Tower Building

323 Center Street

Little Rock, Arkansas 72201

Alex G. Fassbender, P.E.

Senior Manager

Pacific Northwest Laboratories

Battelle Boulevard

Richland, WA 99352

Richard T. Loda

Program Manager, Defense Sciences Offices

ARPA

3701 North Fairfax Drive

Arlington, VA 22203-1714

Crane Robinson

U.S. Army-Armament Research, Development and Engineering Center

SMCAR-AES-P, Bldg 321

Picatinny Arsenal, NJ 07806-5000

D. Hazel Beck

General Atomics

3550 General Atomics Court

P.O. Box 85608

San Diego, CA 92186-9784

1900

D. L. Crawford

5200

E. E. Ives

5300

J. B. Wright

8000 J. C. Crawford

Attn: M. E. John, 8100

R. J. Detry, 8200

W. J. McLean, 8300

L. A. Hiles, 8400

P. E. Brewer, 8500

L. A. West, 8600

R. C. Wayne, 8700 

8113 K. L. Tschritter
8361 J. D. Aiken
8361 D. R. Hardesty
8361 R. G. Hanush
8361 S. F. Rice
8361 R. R. Steeper
8412 H. H. Hirano
8412 M. C. Stoddard
8412 C. A. LaJeunesse (10)
8412 J. P. Chan
8713 B. E. Mills
8535 Publications for OSTI (10)
8535 Publications/Technical Library Processes, 7141
7141 Technical Library Processes Department (3)
8523-2 Central Technical Files (3) 



12
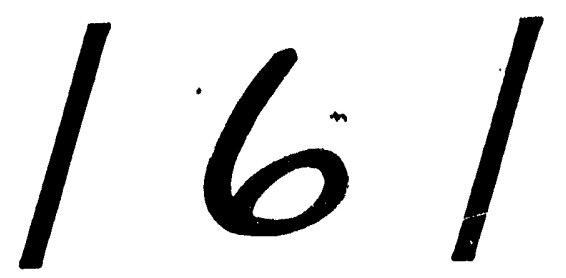

93

